\title{
Very High Cycle Fatigue Properties of 18CrNiMo7-6 Carburized Steel with Gradient Hardness Distribution
}

\author{
Shaopeng Yang ${ }^{1,2, *}$, Peifeng Cheng ${ }^{1,3}$, Fangzhong $\mathrm{Hu}^{2}$, Wenchao $\mathrm{Yu}^{1}$, Chi Zhang ${ }^{4}$, Kaizhong Wang ${ }^{2}$ \\ and Maoqiu Wang $1, *$
}

1 Institute of Special Steel, Central Iron and Steel Research Institute (CISRI), Beijing 100081, China; chengpeifeng_1@163.com (P.C.); yuwenchao@nercast.com (W.Y.)

2 Technical Center, Masteel Co., Ltd., Ma'anshan 243000, China; fangzhonghu@163.com (F.H.); wkzzkwwkz@sina.com (K.W.)

3 School of Materials Science and Engineering, Kunming University of Science and Technology, Kunming 650093, China

4 Key Laboratory of Advanced Materials of Ministry of Education, School of Materials Science and Engineering, Tsinghua University, Beijing 100084, China; chizhang@tsinghua.edu.cn

* Correspondence: yangshaopengpm@foxmail.com (S.Y.); maoqiuwang@hotmail.com (M.W.)

check for updates

Citation: Yang, S.; Cheng, P.; Hu, F.; Yu, W.; Zhang, C.; Wang, K.; Wang, M. Very High Cycle Fatigue Properties of 18CrNiMo7-6 Carburized Steel with Gradient Hardness Distribution. Coatings 2021, 11, 1482. https:// doi.org/10.3390/coatings11121482

Academic Editor: Pier Luigi Bonora

Received: 15 August 2021

Accepted: 23 October 2021

Published: 2 December 2021

Publisher's Note: MDPI stays neutral with regard to jurisdictional claims in published maps and institutional affiliations.

Copyright: (c) 2021 by the authors. Licensee MDPI, Basel, Switzerland. This article is an open access article distributed under the terms and conditions of the Creative Commons Attribution (CC BY) license (https:// creativecommons.org/licenses/by/ $4.0 /)$.

\begin{abstract}
As research of the high cycle fatigue of carburized gear steel could not meet the status quo of longer and longer service lives, research of very high cycle fatigue (VHCF) performance has become the focus of current research. The VHCF properties of case-hardening steel 18CrNiMo7-6 after being carburized with gradient hardness distribution were investigated by means of ultrasonic fatigue tests. The results showed that the carburized specimens with a case hardness of $705 \mathrm{HV}$ and core hardness of $530 \mathrm{HV}$ showed VHCF phenomenon, and the fatigue lives continuously increased to even $10^{9}$ cycles as the stress amplitude decreased to about $500 \mathrm{MPa}$. Observations of the fracture surfaces of the fatigue specimens showed that the fatigue crack initiation sites were located in the transition area with the hardness at about $580 \mathrm{HV}$. It was found that the transition area had low VHCF properties, since the core did not show VHCF phenomenon, and the case had a higher hardness. A fine microstructure was observed in the granular bright facet (GBF) area, and the stress intensity factor $\Delta \mathrm{K}_{\mathrm{GBF}}$ was measured to be $3.04 \mathrm{MPa} \cdot \mathrm{m}^{-1 / 2}$. The $10^{9}$ cycles fatigue life was predicted based on the inclusion size, and the $10^{10}$ cycles fatigue life was $490 \mathrm{MPa}$ based on the prediction model.
\end{abstract}

Keywords: carburized gear steel; very high cycle fatigue; stress intensity factor; fatigue prediction model

\section{Introduction}

The high-frequency facilities uesd to study the VCHF performance of homogeneous materials have become a subject of extensive research in recent decades. Researchers found that when the fatigue life was beyond $10^{9}$ cycles, fatigue failure could still occur and that the conventional high cycle fatigue limit could not reflect from the VHCF S-N data [1-3]. The high cycle fatigue of bearing steel and some high-strength steels had obvious fatigue limits, but the cycle life of VHCF still increased with the decrease of the stress amplitude [4,5]. Sakai et al. [6] reported ultra-high cycle fatigue properties of SUJ2 steel by rotary bending fatigue specimens and found a double S-N curve. Under high stress, the crack initiated on the surface, but under low stress, the failure still occurred, and the crack initiated in the interior of the sample. A granular bright facet (GBF) region was formed around the internal nonmetallic inclusion beyond $10^{6}$ cycles and then extended into the fisheye zone. Sakai et al. [7] studied the ultra-high cycle fatigue of SUJ steel through axial loading specimens, and the S-N curve showed a single line tendency. For ultra-high cycle fatigue, the formation of a GBF region, namely fine granular area (FGA) or optical dark area (ODA), became a typical feature [8,9], so the regions of GBF were called the crack initiation characteristic zones of ultra-high cycle fatigue. In addition, many researchers have revealed 
that the GBF region consumed the majority of the total fatigue failure cycle numbers [10-12]. The life consumed by the GBF region was even higher than $99 \%$ when the total fatigue life was beyond $10^{8}$ cycles [10].

The formation mechanism of the crack initiation characteristic region has become the focus of research on ultra-high cycle fatigue. Hong et al. [13,14] reported the microstructure distribution and formation mechanism of a GBF region of high-strength steel under ultra-high cycle fatigue and proposed the numerous cyclic pressing (NCP) model of the nanograin layer in the crack initiation region and indicated that repeated cyclic stress was the main reason for the formation of a nanograin layer in the GBF region. After carburizing, the surface of carburized gear steel has a hardness gradient, which makes the study of ultrahigh cycle fatigue more complicated [15-17]. Nehila et al. [18,19] indicated the ultra-high cycle fatigue performance of case-hardened steel with a hardness gradient in the early stage and found that the failure of the fatigue specimens would still occur beyond $10^{7}$ cycles, and the stress amplitude of the surface failure was much higher than that of the internal failure. Marines Garcia et al. [20] showed the growth mechanism of a short crack to a long crack in SAE8620 gear steel under ultra-high cycle fatigue failure. Li et al. [21] studied the crack initiation mechanism of carburized gear steel. The failure process of ultra-high cycle fatigue was proposed as the inclusion of a fine granular area (FGA) - fisheye (FIE), final crack growth zone (FCGZ), and material failure zone (MFZ), and the life was predicted.

In a previous work, we investigated the VHCF properties of case-hardening steel with thorough-carburized specimens for cases with pseudo-carburized specimens for the core [22]. Some differences were found for the two kinds of specimens, and the carburized cases should be the weak location, since the pseudo-carburized specimens did not show the VHCF fatigue phenomenon. It is still unclear whether VHCF failure could occur or not and where the weak location was for carburized specimens with gradient hardness distribution. It is also needed to investigate the VHCF behavior of carburized specimens with gradient hardness distribution for real gears always carburized with a gradient hardness distribution. As the core component of carburized gear steel $18 \mathrm{CrNiMo} 7-6$ used in heavy-duty locomotive and rail transit, and the demand for the long lives of these important components, it is particularly important to study the ultra-high cycle fatigue life performance of carburized gear steel 18CrNiMo7-6 [23,24].

\section{Materials and Methods}

The experiment materials used in this investigation were low-carbon gear steel, and the composition is listed in Table 1. All the specimens from 80-mm-diameter hot-rolled bars were machined hour-glass shapes with finishing margins. Then, the carburizing heat treatment process was conducted, as shown Figure 1 . The specimens were carburized at $930{ }^{\circ} \mathrm{C}$ firstly at a carbon potential of $1.20 \%$ for $6.5 \mathrm{~h}$ and, then, at a carbon potential of $0.68 \%$ for $6 \mathrm{~h}$, followed by carbon diffusion at $860^{\circ} \mathrm{C}$ for $1 \mathrm{~h}$. The gas-quenching specimens were then tempered at $650{ }^{\circ} \mathrm{C}$ for $2 \mathrm{~h}$ and air-cooled. After being tempered, the specimens were heated at $840{ }^{\circ} \mathrm{C}$ for $2 \mathrm{~h}$ and oil-quenched in a furnace (Beijing Research Institute of Mechanical \& Electrical Technology, Beijing, China) with a carbon potential of $0.70 \%$ to avoid decarburization. At last, the twice-low-temperature tempering was conducted at $180^{\circ} \mathrm{C}$ for $6 \mathrm{~h}$. After the carburizing heat treatment, all the specimens were finely ground to the final dimensions of the USF2000 ultrasonic fatigue testing machine (Shimadzu, Kyoto, Japan) to ensure surface accuracy and axiality, as shown in Figure 2.

Table 1. 18CrNiMo7-6 chemical composition (wt.\%).

\begin{tabular}{ccccccccc}
\hline Element & C & Si & Mn & P & S & Cr & Ni & Mo \\
\hline 18CrNiMo7-6 & $0.16 \sim 0.19$ & $0.15 \sim 0.35$ & $0.45 \sim 0.65$ & $\leq 0.0015$ & $\leq 0.0020$ & $1.50 \sim 1.80$ & $1.40 \sim 1.70$ & $0.20 \sim 0.30$ \\
\hline
\end{tabular}




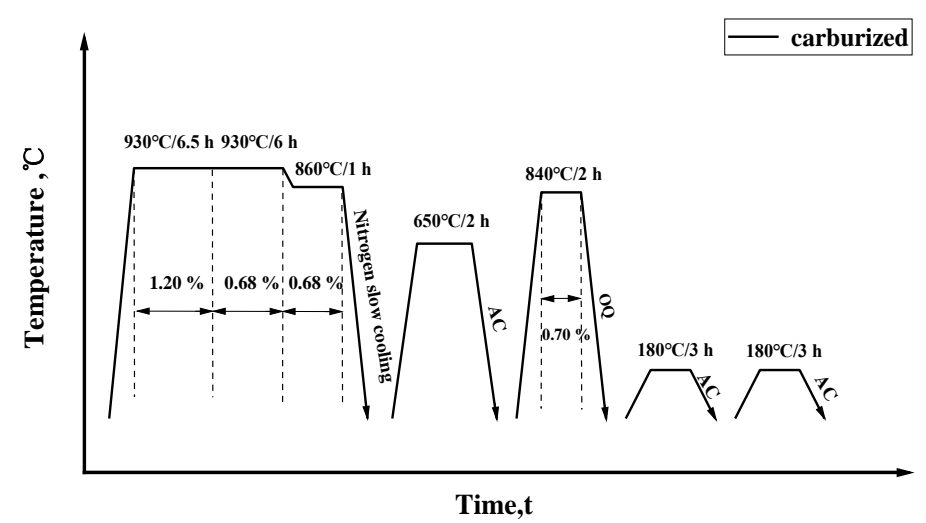

Figure 1. Carburizing heat treatment process, and the underlined data indicates the carbon potential.

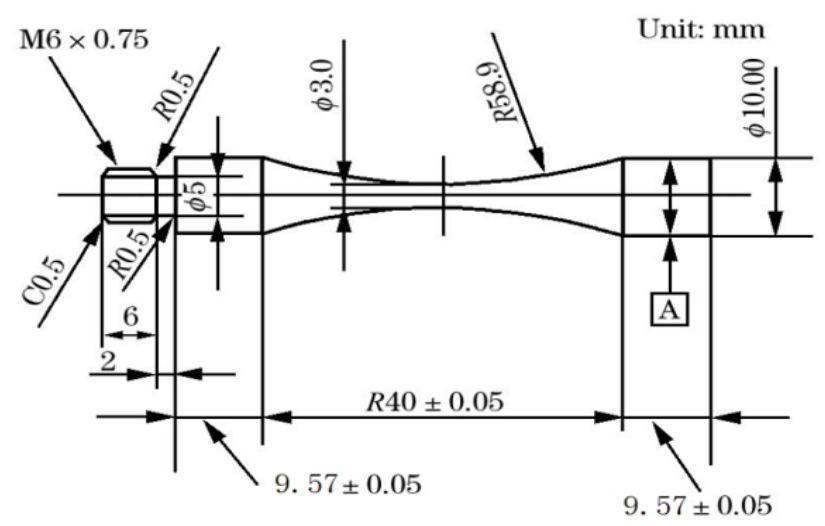

Figure 2. Final machined dimensions and shape of the specimen.

In order to better characterize the microstructure of the specimens after carburizing, several $20 \mathrm{~mm} \times 20 \mathrm{~mm} \times 30 \mathrm{~mm}$ cuboid metallographic specimens were placed inside the same furnace. The specimens that needed to be characterized were cut by linear cutting. After carburizing, the carburizing layer structure of the specimens was observed by optical microscopy (OM, Olympus GX51, Tokyo, Japan), and the residual austenite content was measured by XRD (Bruker, Karlsruhe, Germany), with martensite by scanning electron microscopy (SEM, FEI Company, Hillsboro, OR, USA). Due to the hardness gradient, the microstructure and carbon contents from the surface to the center were not homogeneous, and the distribution of residual austenite was also different. The retained austenite contents were measured at $0,0.3,0.6,0.9,1.2$, and $1.5 \mathrm{~mm}$ from the surface, respectively. The sectional hardness distribution from the surface to the center was measured using a Vickers hardness tester (Wilson Wolpert, Norwood, MA, USA).

In the present experiment, the ultra-high cycle fatigue test (USF-2000, Shimadzu, Kyoto, Japan) was carried out under axial ultrasonic loading in the VHCF regime. The stress ratio was $R=-1$, and the frequency was about $20 \mathrm{kHz}$. The fatigue test was carried out at room temperature $\left(25^{\circ} \mathrm{C}\right)$. Due to the faster frequency, the stress part of the specimens heated up faster. In order to prevent overheating, compressed air was used for cooling, and an intermittent loading mode of $150 \mathrm{~s}$ was adopted to further decrease the influence of the ultra-high frequency. The fracture morphology and the chemical composition of nonmetallic inclusions were analyzed by scanning electron microscopy (SEM) and energy dispersive X-ray spectrometer (EDS), and the distribution and size of the FIE and GBF regions were measured. Using transmission observation, FIB was used to cut small specimens for the transmission electron microscopy (TEMFEI Company, Hillsboro, OR, USA) test. The TEM and electron back scatter diffraction (EBSD) methods were also used to observe the cross-section of the GBF area of the fracture surface, after the fractured specimen was cut and prepared according to References $[25,26]$. 


\section{Results and Discussion \\ 3.1. Microstructure and Hardness}

Figure 3 presented the microstructural features of the carburized layer on the surface of the carburized specimen, and Figure 4 presented the microstructural features $1.0 \mathrm{~mm}$ away from the surface of the carburized specimen by OM and SEM, respectively. Figure 3 illustrates that the microstructure of the carburized layer consisted of acicular martensite and retained austenite, and carbides could be observed in the carburized layer. Figure 4 shows that the microstructure at $1.0 \mathrm{~mm}$ away from the surface of the carburized specimen mainly consisted of lath martensite and carbide, and there was a little residual austenite and acicular martensite. The microstructure characteristics of these different locations are different mainly because the carbon content of the section is not uniform after the carburizing heat treatment. The carbon content of the surface is the highest, and the carbon content decreases with the distance from the surface and eventually tends to the matrix carbon content [27]. Due to the difference in carbon contents, the martensite phase transformation structure and phase transformation temperature are different [28]. The high carbon will form acicular martensite, and low carbon will form lath martensite. The transformation of high-carbon martensite in the formation process is not complete, with a certain amount of residual austenite and low-carbon martensite with a little amount of residual austenite.

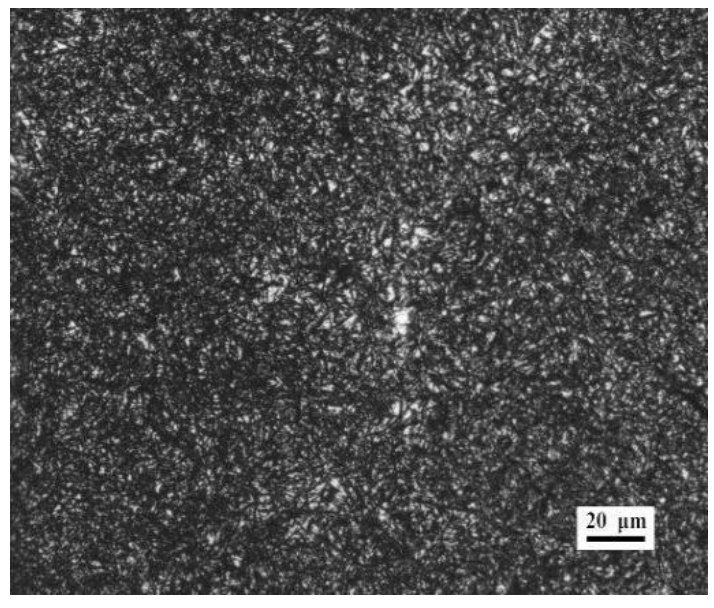

(a)

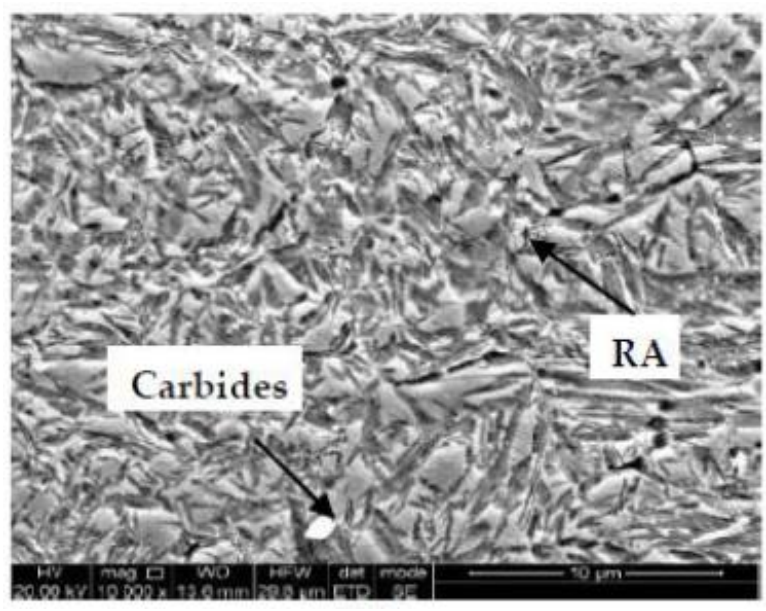

(b)

Figure 3. OM and SEM of the carburizing layer: (a) optical microscope microstructure of the carburizing layer and (b) electron microscope microstructure of the carburizing layer.

Since the surface of the carburized layer contains a large amount of residual austenite, it has a significant effect on the hardness and fatigue. The content of the retained austenite at different depths of the carburized specimen was measured by XRD, with the spectra shown in Figure 5. According to the peak strength measured by XRD, the peak strength of martensite and austenite was calculated by using Jade software, and the content of residual austenite was calculated according to different peak strengths. The maximum residual austenite content of the carburized specimen is $32 \%$ on the largest surface of the specimen, and the residual austenite content decreases gradually with the increase of the depth from the surface. The residual austenite contents at $0.3,0.6,0.9,1.2$, and $1.5 \mathrm{~mm}$ of distance from the sample surface are $21 \%, 11 \%, 11 \%, 4 \%$, and $3 \%$, respectively. From the distribution of the residual austenite content in the carburized layer, the relationship between the residual austenite content and the depth of the carburized layer is nonlinear. The carburization process can increase the surface hardness and improve the fatigue and wear resistance of the material; at the same time, due to the high surface carbon content of carburizing, the residual austenite content of the surface due to high-carbon martensite cannot be completely transformed and increased $[15,29]$. 


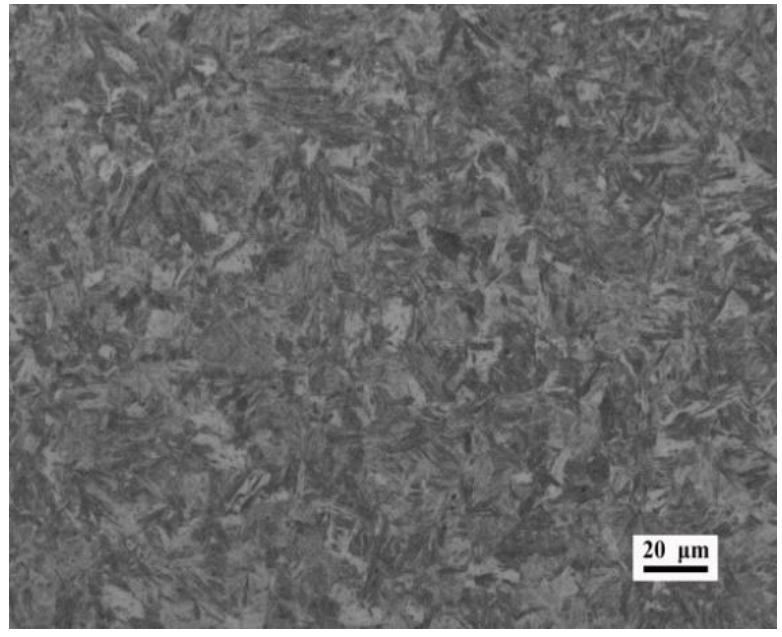

(a)

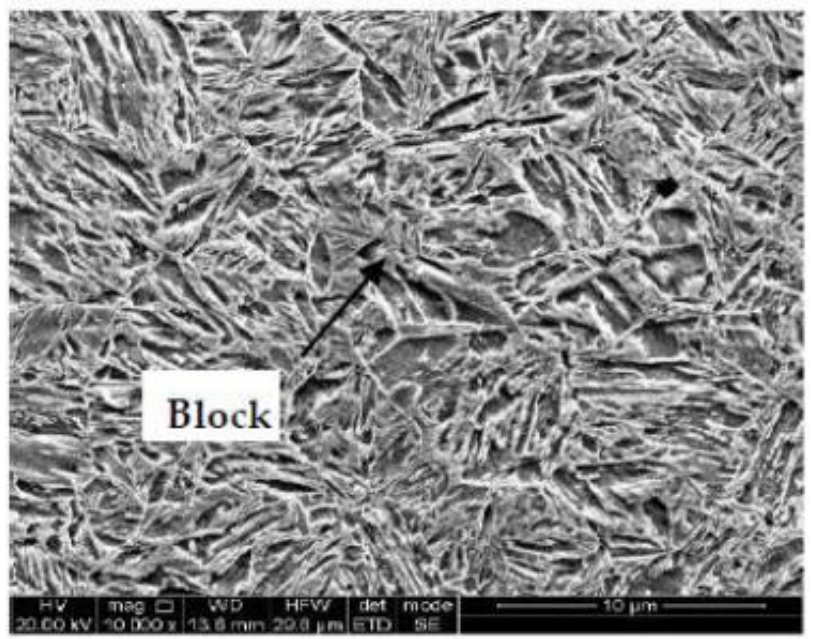

(b)

Figure 4. OM and SEM images of the area $1.0 \mathrm{~mm}$ from the surface: (a) optical microscope microstructure image and (b) scanning electron microscope microstructure image.

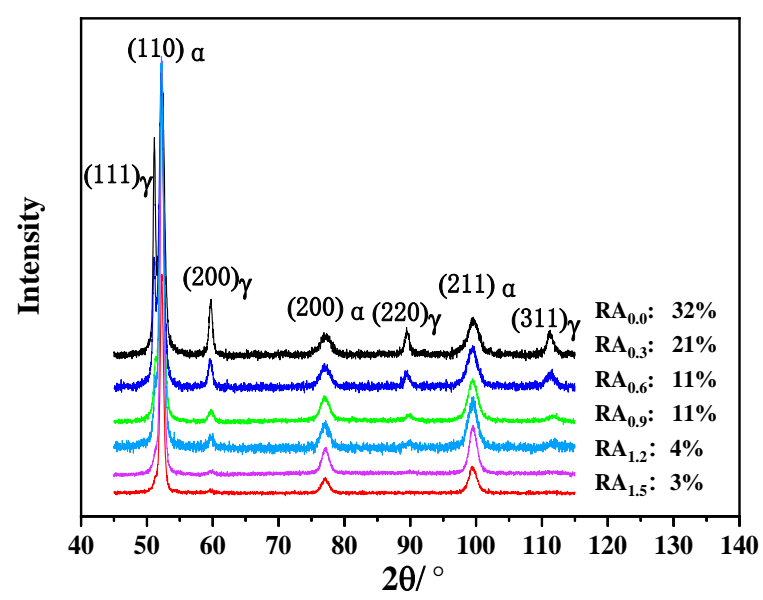

(a)

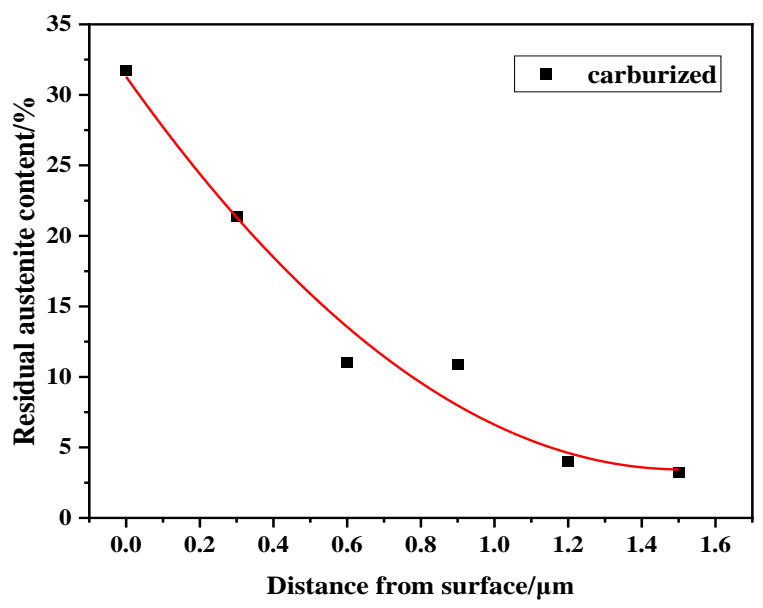

(b)

Figure 5. The XRD patterns of the experimental steel at different depths of $0 \sim 1.5 \mathrm{~mm}$ from the carburized surface show different fractions of retained austenite (RA): (a) XRD RA results and (b) RA changes with the surface distance.

The cross-sectional distribution of the microhardness in the carburized specimen is shown in Figure 6. It can be seen that the hardness decreased linearly with the distance from about $705 \mathrm{HV}$ in the near-surface case to about $530 \mathrm{HV}$ in the core. If a harness of $550 \mathrm{HV}$ is defined as the critical value of hardening, the effective case depth was about $1.4 \mathrm{~mm}$, indicating that the specimens were carburized deeply under the present carburizing process. Compared with the matrix hardness of $442 \mathrm{HV}$ for the experimental steel after pseudo-carburizing [22,30], the hardness of the carburized specimens was remarkably increased by the carburizing treatment. Figure 6 presents the cross-section microhardness of the fatigue specimens after the carburizing process. It can be seen that the hardness decreased linearly with the distance, from about $705 \mathrm{HV}$ in the near-surface case to about $530 \mathrm{HV}$ in the core. If a harness of $550 \mathrm{HV}$ is defined as the critical value of hardening, the effective case depth was about $1.4 \mathrm{~mm}$, indicating that the specimens were carburized deeply under the present carburizing process. Compared with a matrix hardness of $442 \mathrm{HV}$ for the pseudo-carburizing steel [22], the hardness of the carburized specimens was tremendously increased. Zhao et al. [30] indicated that, although the carburization changed the distribution of the microstructure and hardness, the distribution of the elastic 
modulus on the cross-section did not change much, mainly because the elastic modulus was an inherent property of the material, and the elastic modulus was almost constant when the atomic bond was not destroyed.

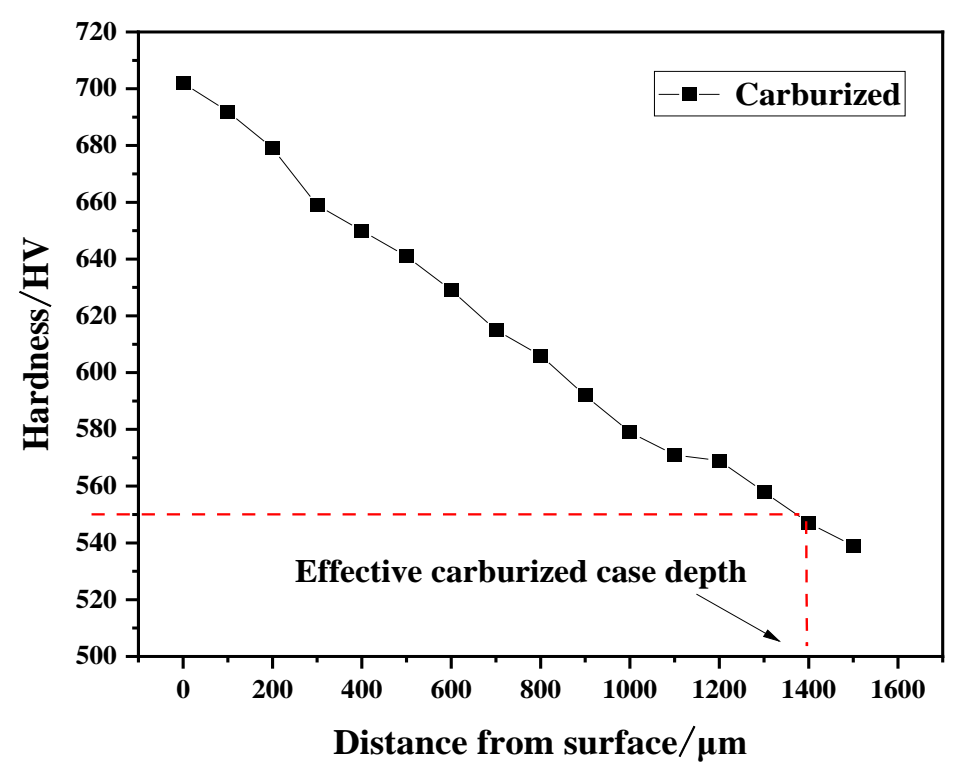

Figure 6. Cross-sectional distributions of microhardness of the experimental steel.

\subsection{S-N Curve}

For a long time, the safety life method has been used to replace the defect tolerance method in the fatigue strength design and analysis of structural members in engineering. The design and analysis procedures are based on smooth specimens obtained from fatigue tests of S-N or Wöhler curves obtained from fatigue testing on smooth specimens. A traditional S-N data curve is characterized by three asymptotic lines. The middle part of the curve, with a constant slope, presents that the fatigue life in terms of the number of cycles to failure Nf increases with the decrease of the stress amplitude. Figure 7 shows the S-N curve of VHCF of carburized gear steel 18CrNiMo7-6 by the up-down method. As shown in Figure 7, with the decrease of the stress amplitude, the number of failure cycles increased gradually. When the stress amplitude was lower than $600 \mathrm{MPa}$, the sample failed beyond $10^{7}$ cycles. The fatigue limit calculated by the up-down method was $510 \mathrm{MPa}$ with the power of $10^{9}$ cycles. When the stress was reduced to $500 \mathrm{MPa}$, the fatigue life exceeded the $10^{9}$ cycles, but the fatigue specimen still did not fail. The curve has an obvious platform, and there is no double S-N curve or continuous descending curve [1,2], which is similar to the traditional fatigue S-N curve [31,32].

\subsection{Fractography}

The typical fracture surfaces of the carburized specimens after the VHCF tests are shown in Figure 8. It can be seen that the fatigue crack initiated from the interior of the specimen with an obvious fisheye feature, as shown in Figure 8a,c. The granular bright facet $(\mathrm{GBF})$ area can be clearly seen around a nonmetallic inclusion, which acted as the crack initiation site (Figure $8 b, d$ ). According to the typical fracture morphology in Figure 8 , the crack initiated in the internal inclusion, and the size of GBF area was different with the distance between the inclusions and the surface, all of which were related to the stress amplitude and cycle times of loading. 


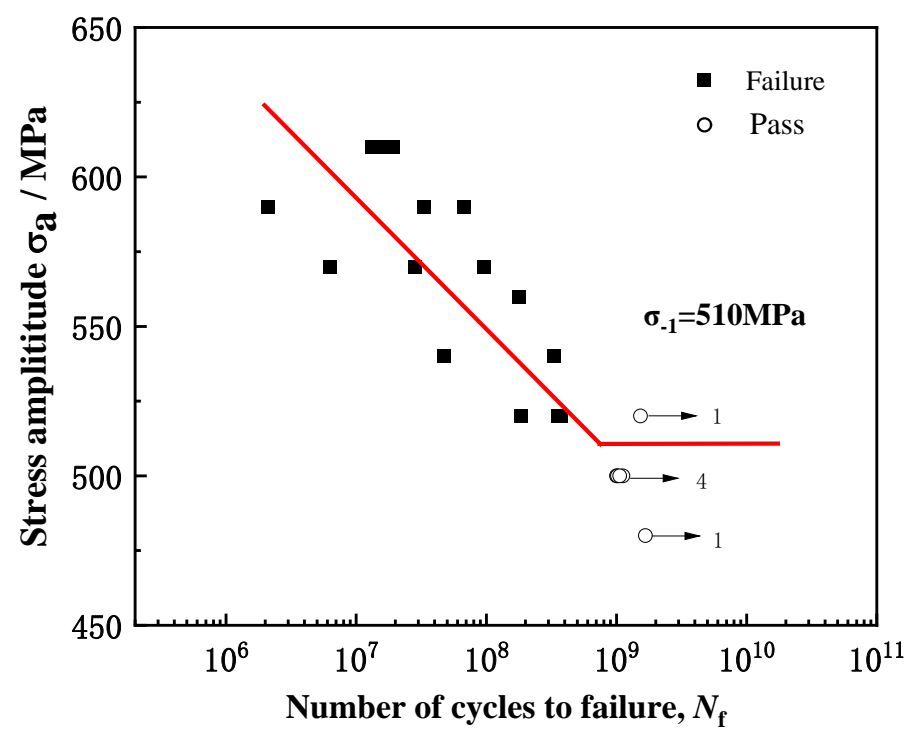

Figure 7. S-N curve of a carburized specimen during an ultra-high cycle.

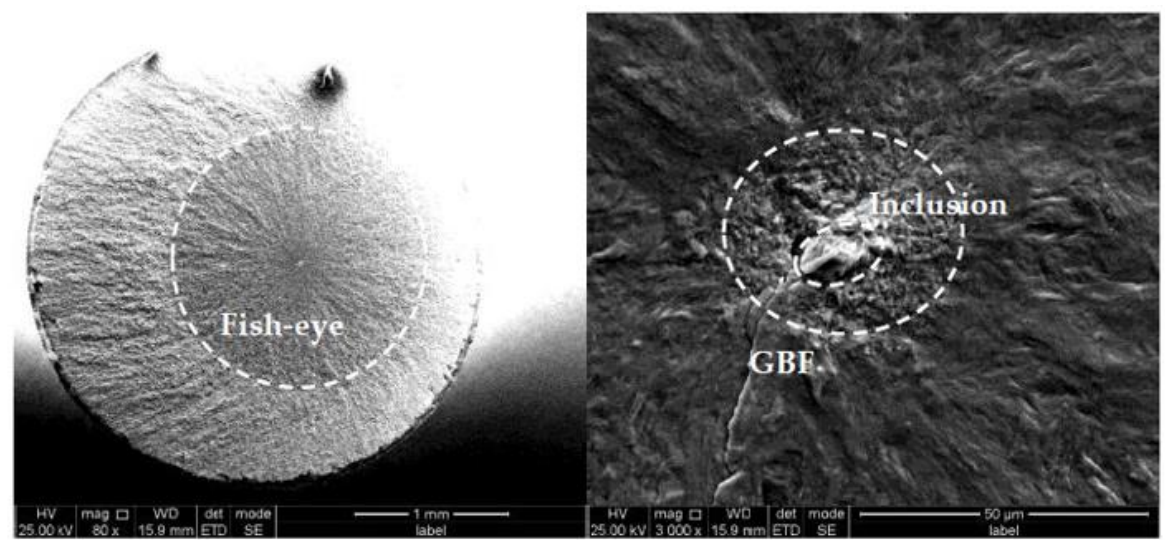

(a)

(b)

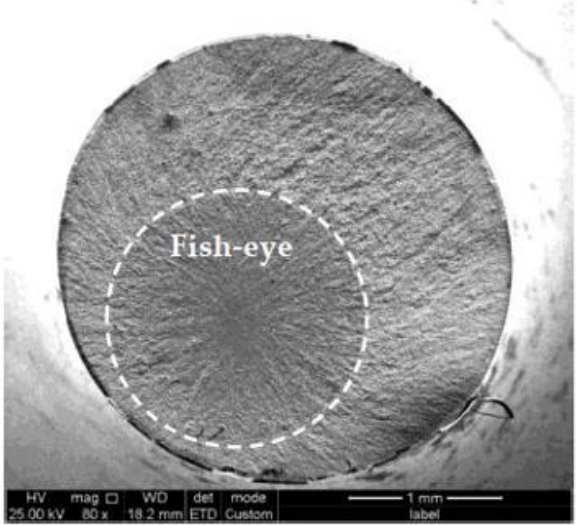

(c)

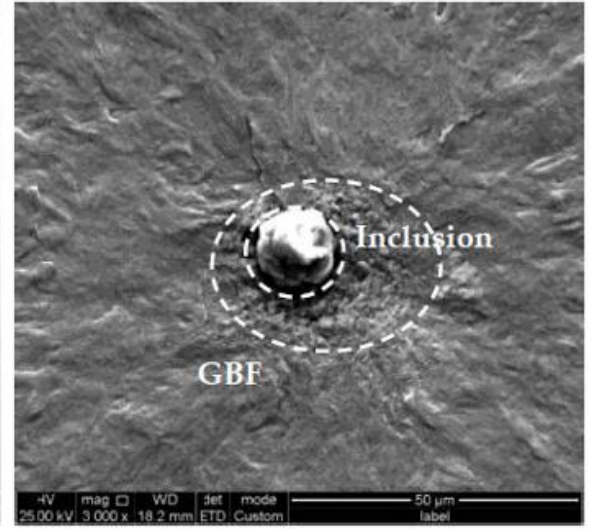

(d)

Figure 8. Typical fracture diagrams of carburized samples during ultra-high cycle fatigue: $(\mathbf{a}, \mathbf{b}) \sigma_{\mathrm{a}}=590 \mathrm{MPa}$ for $\mathrm{N}_{\mathrm{f}}=6.66 \times 10^{7}$ and $(\mathbf{c}, \mathbf{d}) \sigma_{\mathrm{a}}=570 \mathrm{MPa}$ for $\mathrm{N}_{\mathrm{f}}=9.53 \times 10^{7}$.

The VHCF fracture had a GBF characteristic area, so it was particularly important to study the size and properties of the GBF, FIE, and inclusion (Inc.). By SEM observation of the fracture surface, it is found that the GBF is formed around $\mathrm{Al}_{2} \mathrm{O}_{3}$ nonmetallic inclusions containing a scruple Ca element, and the size of the GBF was different under different stress amplitudes and different cycles. The sizes of the inclusion, GBF, and FIE were 
analyzed systematically. The sizes of the inclusion, GBF, and FIE were represented by $\sqrt{\operatorname{area}_{\mathrm{Inc}}}, \sqrt{\operatorname{area}_{\mathrm{GBF}}}$, and $\sqrt{\operatorname{area}_{\mathrm{FiE}}}$, respectively. Are shown in Table 2, it can be seen that the fatigue life increases with the decrease of the stress amplitude, but it is difficult to directly find a relationship between the $\sqrt{\operatorname{area}_{\text {Inc }}}, \sqrt{\operatorname{area}_{\mathrm{GBF}}}$, or $\sqrt{\operatorname{area}_{\mathrm{FiE}}}$ and fatigue life of the specimens. The sizes $\sqrt{\text { area Inc }}$ of the inclusion range from 9 to $39 \mu \mathrm{m}$, with an average value of $22 \mu \mathrm{m}$. The areas $\sqrt{\text { area }_{\mathrm{GBF}}}$ of the GBF range from 22 to $86 \mu \mathrm{m}$, with an average value of $39 \mu \mathrm{m}$. The average size of area $\sqrt{\operatorname{area}_{\mathrm{FiE}}}$ was $1549 \mu \mathrm{m}$ and ranged from 1138 to $1918 \mu \mathrm{m}$.

Table 2. Data of the VHCF fracture origins measured from the fracture surfaces.

\begin{tabular}{ccccccc}
\hline No. & $\begin{array}{c}\text { Stress } \\
/ \mathbf{M P a}\end{array}$ & $\begin{array}{c}\mathbf{N}_{\mathbf{f}} \\
/ \text { Cycle }\end{array}$ & $\begin{array}{c}\sqrt{\mathbf{a r e a} \text { Inc }} \\
/ \mu \mathbf{m}\end{array}$ & $\begin{array}{c}\sqrt{\mathbf{a r e a}_{\mathrm{GBF}}} \\
/ \mu \mathbf{m}\end{array}$ & $\begin{array}{c}\sqrt{\mathbf{a r e a}} \\
/ \mu \mathbf{m i E}\end{array}$ & $\begin{array}{c}\text { Depth } \\
/ \mu \mathrm{m}\end{array}$ \\
\hline 1 & 560 & $1.79 \times 10^{8}$ & 17.00 & 39.12 & 1488 & 947 \\
2 & 540 & $4.75 \times 10^{7}$ & 15.60 & 36.29 & 1751 & 1406 \\
3 & 520 & $3.57 \times 10^{8}$ & 29.46 & 29.85 & 1693 & 1212 \\
4 & 520 & $3.74 \times 10^{8}$ & 10.42 & 42.76 & 1918 & 1378 \\
5 & 540 & $3.29 \times 10^{8}$ & 37.99 & 86.52 & 1869 & 1290 \\
6 & 520 & $1.83 \times 10^{8}$ & 34.85 & 51.25 & 1138 & 646 \\
7 & 500 & $2.26 \times 10^{7}$ & 33.52 & 49.87 & 1690 & 1340 \\
8 & 520 & $2.32 \times 10^{6}$ & 38.84 & 38.84 & 1610 & 1106 \\
9 & 520 & $1.67 \times 10^{7}$ & 26.85 & 34.37 & 1680 & 1269 \\
10 & 570 & $2.82 \times 10^{7}$ & 21.21 & 37.36 & 1304 & 933 \\
11 & 570 & $6.33 \times 10^{6}$ & 38.95 & 43.15 & 1440 & 916 \\
12 & 570 & $9.53 \times 10^{7}$ & 12.35 & 29.79 & 1420 & 953 \\
13 & 590 & $6.66 \times 10^{7}$ & 9.01 & 36.47 & 1540 & 1192 \\
14 & 590 & $2.09 \times 10^{6}$ & 22.01 & 22.01 & 1510 & 1215 \\
15 & 590 & $3.32 \times 10^{7}$ & 12.02 & 29.53 & 1512 & 1173 \\
16 & 610 & $1.91 \times 10^{7}$ & 21.05 & 46.55 & 1160 & 650 \\
17 & 610 & $1.56 \times 10^{7}$ & 15.25 & 26.40 & 1536 & 1091 \\
18 & 610 & $1.32 \times 10^{7}$ & 12.19 & 28.86 & 1629 & 1350 \\
\hline
\end{tabular}

Figure 9 shows the depth of the VHCF crack initiation sites from the carburized surface against the number of cycles to failure. It can be seen that most of the crack initiation sites of the fracture specimens were located at a depth of 0.9-1.4 $\mathrm{mm}$. It can be seen from the hardness distribution curve that this region is a transition zone with an average hardness of $580 \mathrm{HV}$. We tried to find out the relationship between the area size of the GBF and the location of initiation but failed to find a direct relationship. In other words, there was no obvious correlation between the size of the GBF area and the crack initiation position, which was random and may be related to different stress amplitudes and the loading stress of damaged samples. Ultra-high cycle fatigue stress belongs to axial loading stress, namely the tension and compression fatigue test. Theoretically, the stress level is even throughout the whole section of the specimen. Numerical analyses of the static tests showed that the highest level of stress one can find was in the center of the cylindrical specimen, but in the case of fatigue after some cycles, the maximum stress could be found close to the free surface. The carburized specimens had a hardness gradient, the closer it was to the surface, the higher the carbon content, the higher the martensite hardness and microhardness, and the higher the strength, which had a protective effect on the fatigue. The hardness and strength decreased with the increasing distance from the surface, and weakened the protection effect on fatigue failure. 


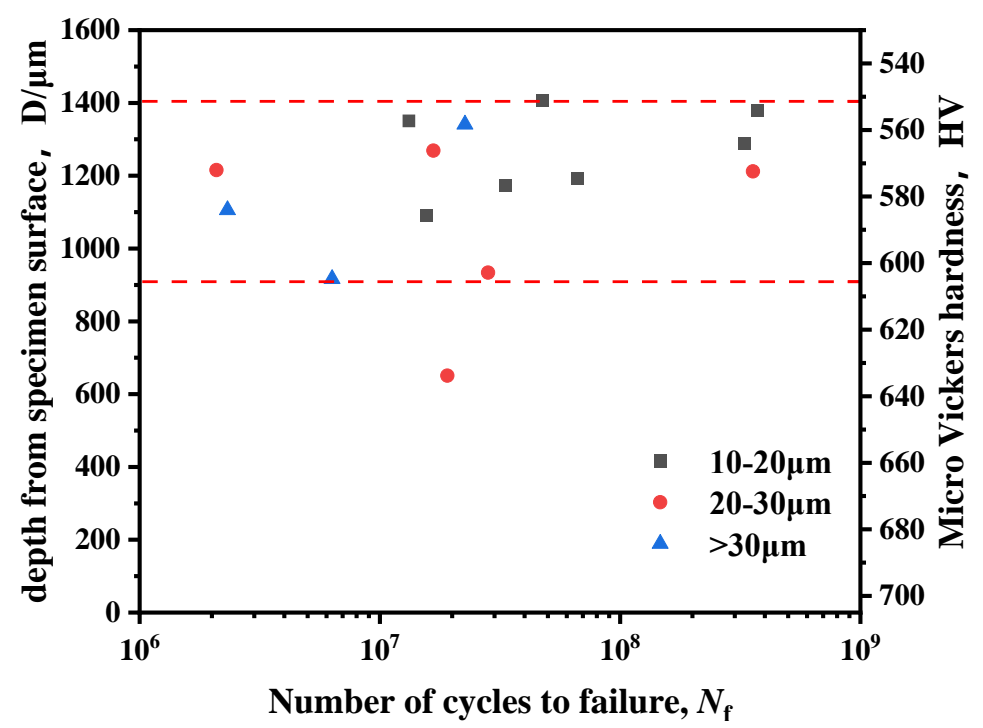

Figure 9. The relationship between the inclusion depth from the specimen surface, Vickers hardness, and number of cycles to failure.

\subsection{Detailed Characterization of GBF and Discussion}

Figure 10 shows a TEM image together with selected area diffraction (SAD) patterns of the cross-section and GBF for a carburizing specimen around the inclusion, which was fractured beyond $10^{7}$ cycles under a $590 \mathrm{MPa}$ stress amplitude. During a TEM analysis of the longitudinal profile, the fracture surface could be roughly divided into the GBF region, transition region, and matrix. GBF region I was the refined nanograin, the transition region was the partially refined microstructure, and the final region, III, was the martensite of the matrix, as shown in Figure 10a. It could also be found that the width of the GBF region varied due to the "unevenness" of the fracture, and its average value was about $500 \mathrm{~nm}$. According to the comparison of light and dark fields in Figure 10b,c, it could be seen that the GBF region and matrix had two different tissue forms. In Figure 10d, it specified the location of the selected area diffraction, showing that the location near the fracture zone was a continuous polycrystalline diffraction ring. It indicated that the nanocrystals formed during the fatigue process under high stress and plastic strain. Below the fracture was greater than $400 \mathrm{~nm}$ (transition area), which was a $5^{\circ}$ misalignment angle diffraction spot, which showed that the plastic deformation of the grains at that position was small. It could be seen that the facture surface in the GBF area was rough, and the near-surface area was much finer than the areas deeper beneath the surface, where martensitic laths could be clearly observed in the center and right sides of the image.

Hong et al. [13] proposed a large number of cyclic pressing (NCP) models to explain the formation mechanism of the GBF on the basis of revealing the microscopic properties of the crack initiation region. Fatigue crack initiation may occur due to the evolution of the local plastic deformation near the activated inclusion after the initial loading period. Crack wakes are subjected to repeated extrusion by cyclic loading, which is related to crack closure [33] and residual stress release [34]. Under the action of the local concentrated plastic deformation, the microstructure of the crack surface layer will fracture and form nanoparticles. This process continues, and after millions of loading cycles, the crack surface becomes a thin layer of coarse nanoparticles. Under the transient conditions from crack initiation to steady-state propagation, the NCP process terminates and reaches the critical size of the GBF. According to the morphology of the GBF region represented in Figure 10, it basically conformed to the NCP model, and a large number of dislocation aggregation can be observed in Figure 10c, which proved that, under a large amount of cyclic stress, a certain internal plastic deformation led to a dislocation movement. 

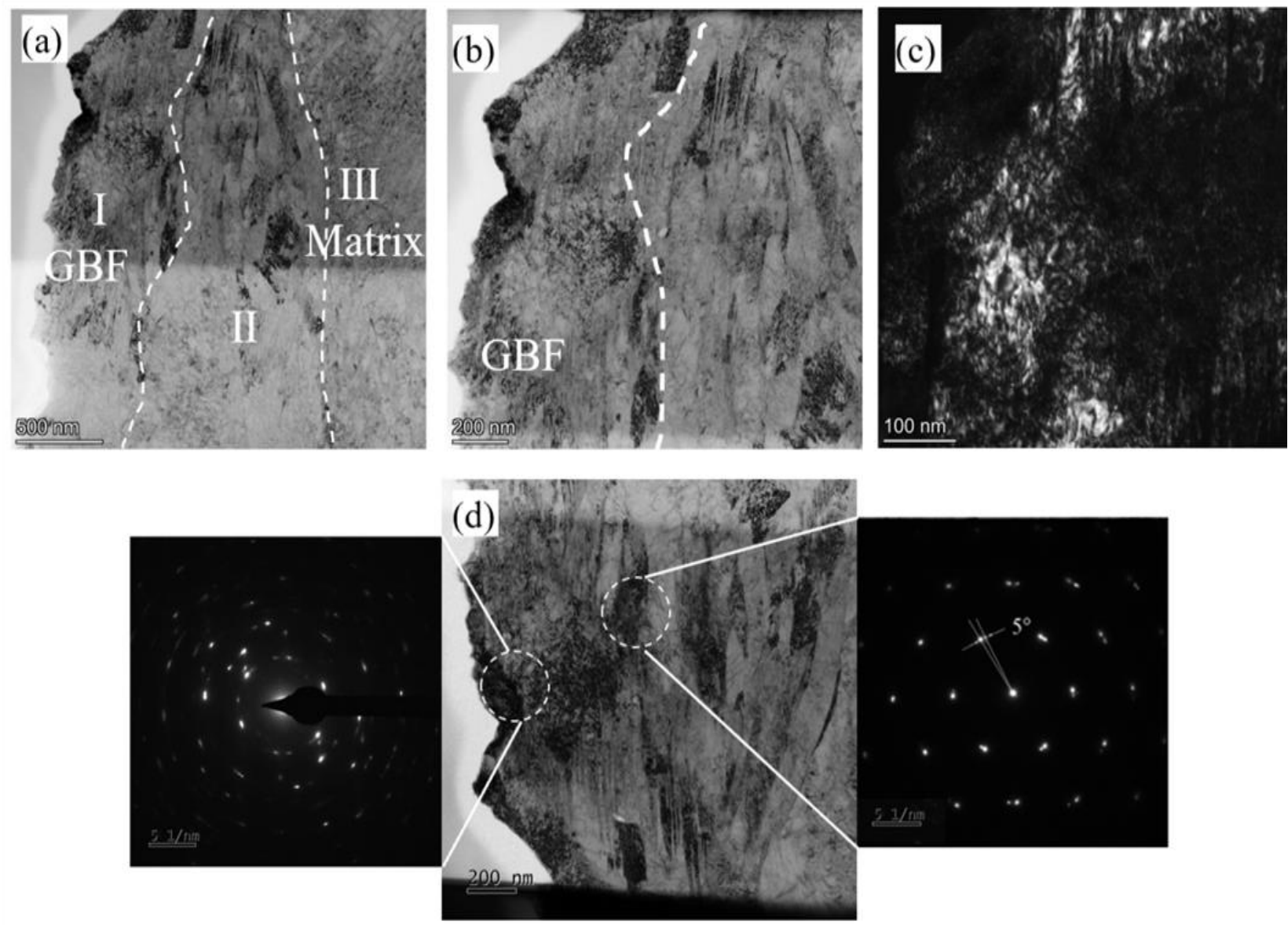

Figure 10. TEM bright field image together with the SAD patterns in the GBF area of the carburized specimen after the VHCF tests at $\sigma_{\mathrm{a}}=590 \mathrm{MPa}$ for $\mathrm{N}_{\mathrm{f}}=6.66 \times 10^{7}$. (a) is transmission morphology of GBF region, transition region and matrix, (b) is transmission morphology of GBF region, (c) is GBF region transmission amplification morphology, (d) is the location of the selected area diffraction.

Figure 11 shows a TEM image with the morphology of carbide precipitation near the crack origin. The precipitates are $\mathrm{Cr}$-rich carbides in long strip forms in the matrix. Cr-rich carbides have lower dissolution temperatures, and most of them dissolve after carburizing for a long time. However, the carbides precipitated after high-temperature tempering were not completely dissolved in the subsequent short austenitizing, and the undissolved carbides were distributed in long strips in the matrix.

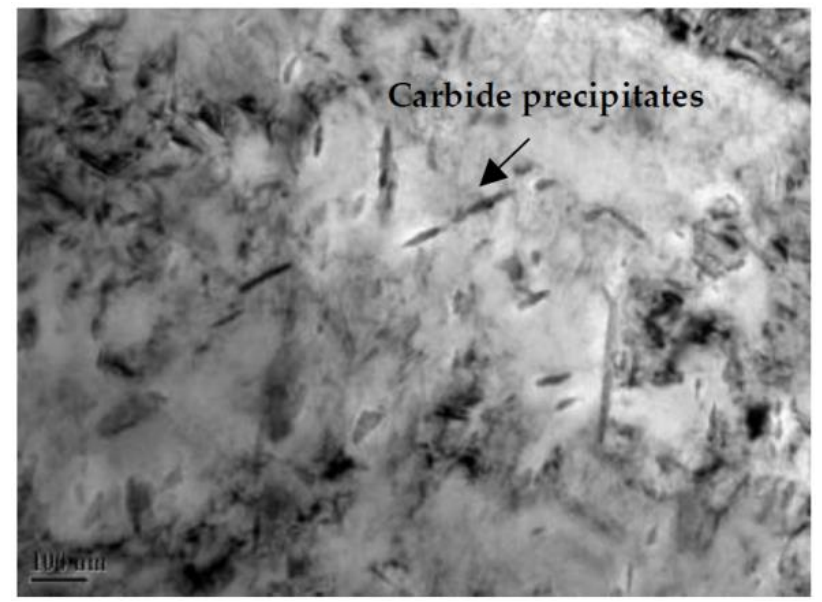

Figure 11. TEM characterization of the carbide precipitates. 
Figure 12 shows EBSD maps of the same carburized specimen cross-section around the inclusion and GBF. It also indicated that the near-surface area was much finer than the areas deeper beneath the surface (Figure 12a). As shown in Figure 12b, retained austenite, as shown by the peak areas, was distributed between the martensitic boundaries. Figure 12 shows that a large number of nanocrystallines exist in the GBF region, which is consistent with the transmission results, further verification that nanocrystalline layers are formed around inclusions under millions of cycles of ultra-high cycle fatigue.

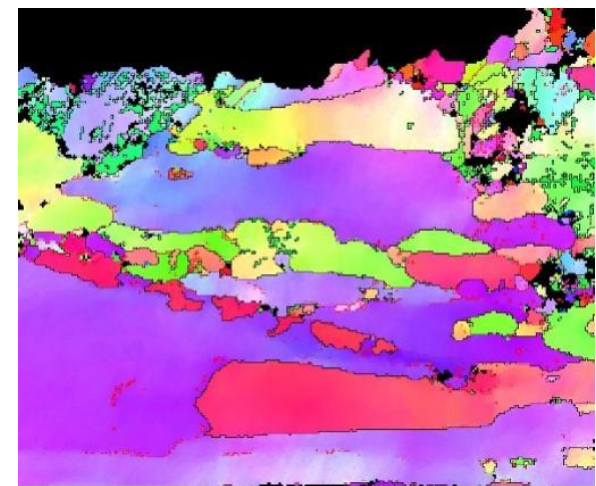

(a)

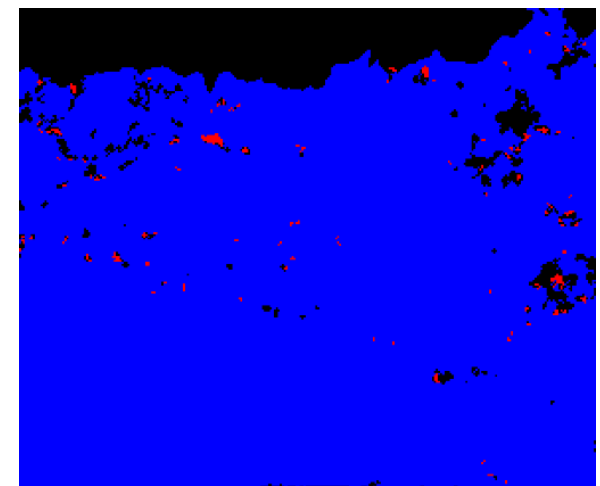

(b)

Figure 12. EBSD map showing the fracture surfaces of the carburized specimens after VHCF tests at $\sigma_{\mathrm{a}}=590 \mathrm{MPa}$ for $\mathrm{N}_{\mathrm{f}}=6.66 \times 10^{7}$. (a) The near-surface area microstructure and (b) the near-surface area RA.

\subsection{Stress Intensity Factor}

By calculating the stress intensity range $\Delta \mathrm{K}$, the influence of the inclusion, GBF, and FIE on the fatigue life and fatigue strength was studied. The calculation formula is as follows:

$$
\Delta \mathrm{K}=0.5 \Delta \sigma \sqrt{\pi \sqrt{\text { area }}}, \Delta \sigma=2 \sigma_{\mathrm{a}}
$$

where $\sqrt{\text { area }}$ is a crack size defined as the square root of the measurement area, and $\sigma_{a}$ is the stress amplitude. Figure 13 shows the relationship between the stress intensity factor $\Delta \mathrm{K}$ and fatigue life $\mathrm{N}_{\mathrm{f}}$. The crack propagation process of the fatigue specimens was GBFFIE-FCGZ-MFZ [21], where $99 \%$ of the life of the crack initiation was mainly consumed in the GBF region [10], and $\Delta \mathrm{K}_{\mathrm{GBF}}$ can be regarded as the threshold value $\Delta \mathrm{K}_{\mathrm{th}}$ [21] of the crack initiation. When the stress intensity factor at the crack edge was $\Delta \mathrm{K}<\Delta \mathrm{K}_{\text {th }}$ the fatigue short crack did not expand and directly formed a fisheye; when $\Delta \mathrm{K}>\Delta \mathrm{K}_{\mathrm{th}}$, the short crack formed a GBF nanograin layer. Similarly, $\Delta \mathrm{K}_{\mathrm{FiE}}$ can also be regarded as the critical value of crack growth. When $\Delta \mathrm{K}<\Delta \mathrm{K}_{\mathrm{FiE}}$, the fatigue long crack did not grow, and a fatigue fracture occur suddenly. As indicated in Figure 13a,b, the values of $\Delta \mathrm{K}_{\mathrm{GBF}}$ and $\Delta \mathrm{K}_{\mathrm{FiE}}$ did not change with the increase of $\mathrm{N}_{\mathrm{f}}$ but fluctuated within a small range, which was consistent with the research results of many researchers [31,32].

It assumed that $\Delta \mathrm{K}_{\mathrm{GBF}}$ and $\Delta \mathrm{K}_{\mathrm{FiE}}$ were regarded as constants; the average values of $\Delta \mathrm{K}_{\mathrm{GBF}}$ and $\Delta \mathrm{K}_{\mathrm{FiE}}$ after the carburization of low-carbon gear steel 18CrNiMo7-6 were 3.04 and $20 \mathrm{MPa} \cdot \mathrm{m}^{-1 / 2}$, respectively. According to the above analysis, the threshold value formed by the GBF region was far less than that formed by FIE, and it was inevitable that the crack front end of the GBF grew slowly, thus consuming most of the fatigue life. At low cyclic stresses of millions of times, the dislocations moved and piled up, further slowing down the propagation of short cracks. The value of $\Delta \mathrm{K}_{\mathrm{Inc}}$ decreased with the increase of $\mathrm{N}_{\mathrm{f}}$, while $\mathrm{N}_{\mathrm{f}}$ increased only when the stress amplitude decreased; that is, in the case of low stress, the cracks were first initiated at an inclusion a with small size. As can be seen from Figure $13 \mathrm{c}$, the ratio of $\Delta \mathrm{K}_{\mathrm{GBF}} / \Delta \mathrm{K}_{\mathrm{Inc}}$ increased with the increase of the number of cycles, further indicating that the formation of GBF consumed the vast majority of the life of the VHCF at a lower stress amplitude. 


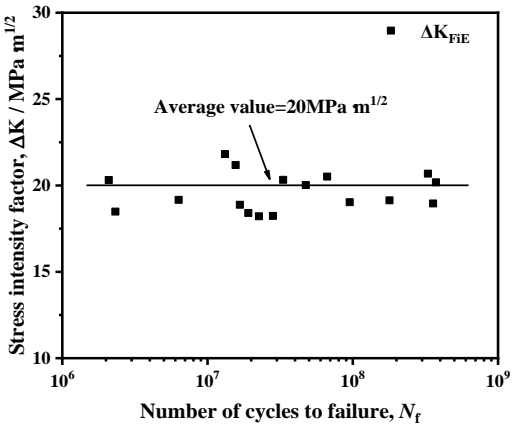

(a)

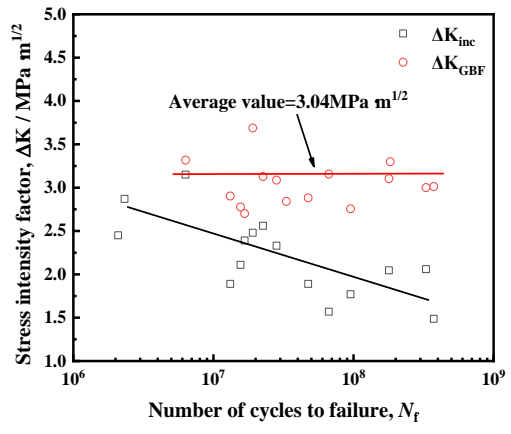

(b)

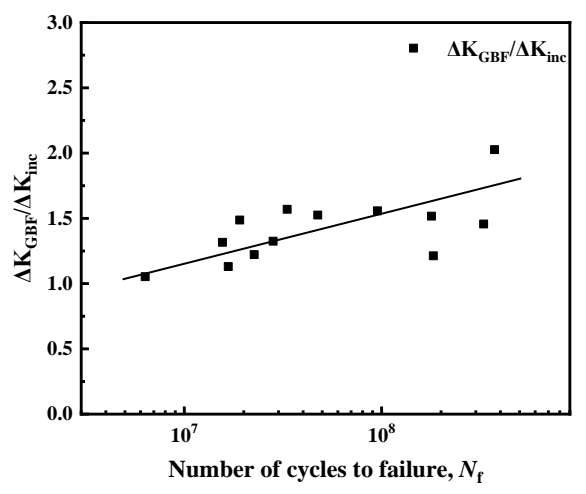

(c)

Figure 13. The relationship between $\Delta \mathrm{K}_{\mathrm{inc}}, \Delta \mathrm{K}_{\mathrm{GBF}}, \Delta \mathrm{K}_{\text {Fish-eye, }}$ and the fatigue life of experimental steel: (a) $\Delta \mathrm{K}_{\text {Fish-eye }}$ changes with the fatigue cycle life, (b) $\Delta \mathrm{K}_{\mathrm{inc}}$ and $\Delta \mathrm{K}_{\mathrm{GBF}}$ changes with the fatigue cycle life, and (c) $\Delta \mathrm{K}_{\mathrm{GBF}} / \Delta \mathrm{K}_{\mathrm{inc}}$ changes with the fatigue cycle life.

Table 3 lists the results of the VHCF limits and $\Delta \mathrm{K}_{\mathrm{GBF}}$ values of some high-strength steels $[22,35,36]$. The VHCF limits of the carburized specimen of the experimental steel were not only lower than those of bearing steel SUJ2 and quenched and tempered steel SNCM439 but also lower than that of the same steel 18CrNiMo7-6 thorough-carburized with the same cross-section hardness of $719 \mathrm{HV}$. The $\Delta \mathrm{K}_{\mathrm{GBF}}$ of the experimental steel was the lowest among the listed steels. Thus, the transition area in the carburized specimen had the lowest VHCF properties than both cases, which had a high hardness and core that did not show the VHCF phenomenon, as reported in a previous study [22]. This indicates that much attention should be paid to the transition area for real carburized gears with very high cycle life requirements in service.

Table 3. Comparison of the VHCF limits and $\Delta \mathrm{K}_{\mathrm{GBF}}$ values of high-strength steels.

\begin{tabular}{ccccc}
\hline Steel & $\begin{array}{c}\boldsymbol{\sigma}_{-\mathbf{1}} \\
/ \mathbf{M P a}\end{array}$ & $\begin{array}{c}\text { Hardness } \\
\text { /HV }\end{array}$ & $\boldsymbol{\Delta K}_{\mathbf{G B F}}$ & Ref. No \\
\hline 18CrNiMo7-6 (Carburized) & 500 & $705-510$ & 3.04 & present \\
18CrNiMo7-6 (Thorough-carburized) & 600 & 719 & 3.49 & {$[22]$} \\
SUJ2 & 765 & 707 & 4.65 & {$[35]$} \\
SNCM439 & 925 & 586 & 4.00 & {$[36]$} \\
\hline
\end{tabular}

\subsection{Fatigue Life Prediction}

Lots of parts reached the fatigue life limit but did not fail, and the cycles of lots of parts in the actual operation process far exceeded the design safety life, all of which brought about enormous safety risks, so the accurate prediction of the fatigue life became the focus of research $[37,38]$. Especially for very high cycle fatigue, it was difficult to evaluate and verify its fatigue safety life through actual service, not only because it would cost a lot of manpower and financial resources but also, in most cases, the time and conditions were not allowed. Furuya revised Tanaka-Akimina's model and proposed a new prediction model of ultra-high cycle fatigue strength [39]. The solid line near the carburizing pattern in Figure 14 is fitted according to this new model. In this fitting, the $\mathrm{R}^{2}$ value (determination coefficient) reflecting the goodness of fit is 0.78 . According to these results, the fatigue life curves (dashed lines) of the minimum inclusion size of $\sqrt{\text { area }}=15 \mu \mathrm{m}$ and the maximum inclusion size $\sqrt{\text { area }}=26 \mu \mathrm{m}$ are predicted, and it can be seen that the measured points are basically between these two curves. The ultra-high cycle fatigue strength of $10^{10}$ cycles is predicted, and the fatigue strength is about $490 \mathrm{MPa}$. However, the accuracy of the $10^{10}$ cycles' fatigue life prediction needs further study. Formula (1) is the new law of crack growth instead of this model. The related formula of this model are as follows:

$$
\frac{\mathrm{d} \sqrt{\text { area }}}{\mathrm{dN}}=\mathrm{C}\left(\Delta \mathrm{K} \times \sqrt{\text { area }}^{\alpha}\right)^{\mathrm{m}}
$$




$$
\begin{gathered}
\sigma_{\mathrm{a}}=\frac{1}{\sqrt{\pi}}(\mathrm{D})^{\frac{1}{\mathrm{~m}}} \times\left(\mathrm{N}_{\mathrm{f}}\right)^{-\frac{1}{\mathrm{~m}}} \times\left(\sqrt{\text { area }_{\text {inc }}}\right)^{\left(\frac{1}{\mathrm{~m}}-\frac{1}{2}-\alpha\right)} \\
\left(\Delta \mathrm{K}_{\text {inc }} \times \sqrt{\text { area }_{\text {inc }}} \alpha\right)^{\mathrm{m}}\left(\frac{\mathrm{N}_{\mathrm{f}}}{\sqrt{\text { area }_{\text {inc }}}}\right)=\frac{2^{1-\mathrm{m}\left(\frac{1}{2}+\alpha\right)}-1}{\mathrm{C}\left(1-\mathrm{m}\left(\frac{1}{2}+\alpha\right)\right.}=\mathrm{D}
\end{gathered}
$$

where $\mathrm{m}, \mathrm{D}$, and $\alpha$ are constants that determine the crack propagation properties. $\mathrm{D}$ is a constant that simplifies the right side of Formula (3). Through nonlinear fitting, we can obtain the parameters for the carburized specimens of the experimental steel as follows: $\mathrm{D}=2.04 \times 1087, \mathrm{~m}=37.17$, and $\alpha=-0.28$.

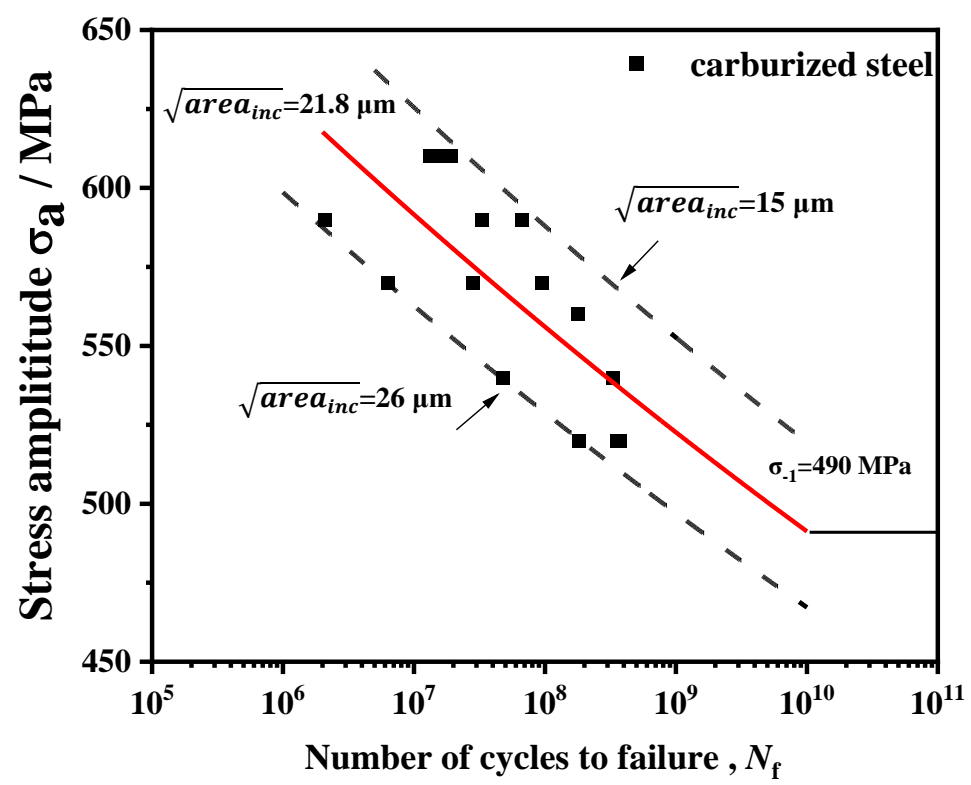

Figure 14. Fatigue S-N curve of the carburized specimens of the experimental steel.

\section{Conclusions}

The VHCF properties of low-carbon gear 18CrNiMo7-6 were studied by means of ultrasonic fatigue tests in this work. The GBF region was characterized in detail, and its formation mechanism was revealed, and the applicability of the fatigue life prediction model for carburized gear steel was verified. The following conclusions can be drawn.

(1) The carburized specimens of the experimental steel showed typical VHCF behavior, and the fatigue limit at the $10^{9}$ cycle was measured to be $500 \mathrm{MPa}$. The VHCF S-N curve could be predicted by a theoretical model taking into account the nonmetallic inclusion sizes.

(2) The fatigue crack initiation sites of the carburized specimens were located mostly in the transition area at a distance of 0.9-1.4 $\mathrm{mm}$ from the surface, where the hardness was about $580 \mathrm{HV}$. It was because the core did not show VHCF phenomena, and the case had a higher hardness.

(3) A fine microstructure was observed in the GBF area by means of TEM and EBSD, and the stress intensity factor value $\Delta \mathrm{K}_{\mathrm{GBF}}$ at the GBF area was measured to be around $3.04 \mathrm{MPa} \cdot \mathrm{m}^{-1 / 2}$. The GBF region was mainly a nanograin layer formed by a small plastic deformation caused by long-time circulation under low stress.

Author Contributions: Conceptualization, S.Y., P.C., C.Z. and M.W. and experiment and data processing, K.W., F.H. and W.Y. All authors have read and agreed to the published version of the manuscript.

Funding: This research was financially supported by Industrial Strong Foundation Engineering (Tender No. TC180A3Y1/Subcontract No. 14).

Institutional Review Board Statement: Not applicable. 
Informed Consent Statement: Not applicable.

Data Availability Statement: Not applicable.

Conflicts of Interest: The authors declare no conflict of interest.

\section{References}

1. Sakai, T.; Lian, B.; Takeda, M.; Shiozawa, K.; Oguma, N.; Ochi, Y.; Nakajima, M.; Nakamura, T. Statistical duplex S-N characteristics of high carbon chromium bearing steel in rotating bending in very high cycle regime. Int. J. Fatigue 2010, 32, 497. [CrossRef]

2. Li, W.; Sakai, T.; Wakita, M.; Mimura, S. Influence of microstructure and surface defect on very high cycle fatigue properties of clean spring steel. Int. J. Fatigue 2014, 60, 48. [CrossRef]

3. Furuya, Y. Gigacycle fatigue properties of double-melted SCM440 steel and size effects. ISIJ Int. 2014, 52, 1436. [CrossRef]

4. Yang, Z.G.; Li, S.X.; Zhang, J.M.; Zhang, J.F.; Li, G.Y.; Li, Z.B.; Hui, W.J.; Weng, Y.Q. On the critical inclusion size of high strength steels under ultra-high cycle fatigue. Acta Mater. 2004, 52, 5235. [CrossRef]

5. Bathias, C.; Drouillac, L.; le Francois, P. How and why the fatigue S-N curve does not approach a horizontal asymptote. Int. J. Fatigue 2001, 23, 143-151. [CrossRef]

6. Sakai, T.; Takeda, M.; Shiozawa, K.; Ochi, Y.; Nakajima, M.; Nakamura, T. Experimental reconfirmation of characteristic S$\mathrm{N}$ property for high carbon chromium bearing steel in wide life region in rotating bending. J. Soc. Mater. Sci. 2000, 49, 779-785. [CrossRef]

7. Sakai, T.; Sato, Y.; Oguma, N. Characteristic S-N property of high carbon chromium bearing steel under axial loading in long life fatigue. Mater. Struct. 2002, 25, 765-773. [CrossRef]

8. Murakami, Y.; Yokoyama, N.N.; Nagata, J. Mechanism of fatigue failure in ultralong life regime. Fatigue Fract. Eng. Mater. Struct. 2002, 25, 735-746. [CrossRef]

9. Hong, Y.; Zhao, A.; Qian, G.; Zhou, C. Fatigue strength and crack initiation mechanism of very-high-cycle fatigue for low alloy steels. Mater. Trans. A 2012, 43, 2753-2762. [CrossRef]

10. Hong, Y.; Lei, Z.; Sun, C.; Zhao, A. Propensities of crack interior initiation and early growth for very-high-cycle fatigue of high strength steels. Int. J. Fatigue 2014, 58, 144-151. [CrossRef]

11. Tanaka, K.; Akiniwa, Y. Fatigue crack propagation behaviour derived from S-N data in very high cycle regime. Fatigue Fract. Eng. Mater. Struct. 2002, 25, 775-784. [CrossRef]

12. Liu, X.; Sun, C.; Hong, Y.S. Effects of stress ratio on high-cycle and very-high cycle fatigue behavior of a Ti-6Al-4V alloy. Hong Mater. Sci. Eng. A 2015, 622, 228-235. [CrossRef]

13. Hong, Y.; Liu, X.; Lei, Z.; Sun, C. The formation mechanism of characteristic region at crack initiation for very-high-cycle fatigue of high-strength steels. Int. J. Fatigue 2016, 89, 108-118. [CrossRef]

14. Yukun, C.; Xiangnan, P.; Liang, Z. Microstructure refinement and grain size distribution in crack initiation region of very-highcycle fatigue regime for high-strength alloys. Int. J. Fatigue 2020, 134, 105473.

15. Krauss, G. The microstructure and fracture of a carburized steel. Metall. Mater. Trans. A 1978, 9, 1527. [CrossRef]

16. Erdogan, M.; Tekeli, S. The effect of martensite volume fraction and particle size on the tensile properties of a surface-carburized AISI 8620 steel with a dual-phase core microstructure. Mater. Charact. 2003, 49, 445. [CrossRef]

17. Liu, Y.; Wang, M.Q.; Shi, J.; Hui, W.J.; Fan, G.; Dong, H. Fatigue properties of two case hardening steels after carburization. Int. J. Fatigue 2009, 31, 292. [CrossRef]

18. Naito, T.; Ueda, H.; Kikuchi, M. Fatigue behavior of carburized steel with internal oxides and nonmartensitic microstructure near the surface. Metall. Mater. Trans. 1984, 15, 1431. [CrossRef]

19. Nehila, A.; Li, W.; Gao, N.; Xing, X.; Zhao, H.; Wang, P.; Sakai, T. Very high cycle fatigue of surface carburized CrNi steel at variable stress ratio: Failure analysis and life prediction. Int. J. Fatigue 2018, 111, 112. [CrossRef]

20. Marines-Garcia, I.; Paris Paul, C.; Tada, H. Fatigue crack growth from small to long cracks in VHCF with surface initiations. Mater. Sci. Eng. A 2007, 468-470, 120-128. [CrossRef]

21. Li, W.; Sun, Z.; Zhang, Z.; Deng, H. Tatsuo Sakai. Influence of case-carburizing and micro-defect on competing failure behaviors of Ni-Cr-W steel under gigacycle fatigue. J. Mater. Res. 2015, 30, 2247-2257. [CrossRef]

22. Cheng, P.F.; Li, Y.K.; Yu, W.C.; Yang, S.P.; Hu, F.Z.; Shi, J.; Wang, M.Q.; Li, L. Comparison of very high cycle fatigue properties of 18CrNiMo7-6 steel after carburizing and pseudo-carburizing. Mater. J. Eng. Perform. 2020, 29, 8340. [CrossRef]

23. Sun, C.; Xie, J.; Zhao, A.; Lei, Z.; Hong, Y.A. cumulative damage model for fatigue life estimation of high-strength steels in high-cycle and very-high-cycle fatigue regimes. Fatigue Fract. Eng. Mater. Struct. 2012, 35, 638-647. [CrossRef]

24. Mayer, H. Recent developments in ultrasonic fatigue. Fatigue Fract. Eng. Mater. Struct. 2016, 39, 3-29. [CrossRef]

25. Wang, C.F.; Wang, M.Q.; Shi, J.; Hui, W.J.; Dong, H. Effect of microstructural refinement on the toughness of low carbon martensitic steel. Scr. Mater. 2008, 58, 492. [CrossRef]

26. Chen, W.; He, X.F.; Yu, W.C.; Shi, J.; Wang, M.Q.; Yao, K.F.; Mater, J. Nano and microhardness distribution in the carburized case of nb microalloyed gear steel. Eng. Perform. 2020, 29, 4626. [CrossRef]

27. Liu, H.; Wang, W.; Zhu, C. A microstructure sensitive contact fatigue model of a carburized gear. Wear 2019, 436-437, 203035. [CrossRef]

28. Shen, Y.; Moghadam, S.; Mobasher, S.F. Effect of retained austenite-Compressive residual stresses on rolling contact fatigue life of carburized AISI 8620 steel. Int. J. Fatigue 2015, 75, 135-144. [CrossRef] 
29. Roy, S.; Sundararajan, S. The effect of heat treatment routes on the retained austenite and tribomechanical properties of carburized AISI 8620 steel. Surf. Coat. Technol. 2016, 308, 236. [CrossRef]

30. Zhao, M.H.; Han, X.C.; Wang, G. Determination of the mechanical properties of surface-modified layer of 18CrNiMo7-6 steel alloys after carburizing heat treatment. Int. J. Mech. Sci. 2018, 148, 84-93. [CrossRef]

31. Hong, Y.; Sun, C. The nature and the mechanism of crack initiation and early growth forvery-high-cycle fatigue of metallic materials-An overview. Theor. Appl. Fract. Mech. 2017, 92, 331-350. [CrossRef]

32. Li, W.; Yuan, H.; Sun, Z. Surface vs. interior failure behaviors in a structural steel under gigacycle fatigue: Failure analysis and life prediction. Int. J. Fatigue 2014, 64, 42-53. [CrossRef]

33. Pippan, R.; Hohenwarter, A. Fatigue crack closure: A review of the physical phenomena. Fatigue Fract. Eng. Mater. Struct. 2017, 40, 471-495. [CrossRef] [PubMed]

34. Sattari-Far, I.; Akbari, D.; Alderliesten, R. Effect of residual stresses on crack behaviour in single edge bending specimens. Mater. Struct. 2013, 36, 115-126.

35. Shiozawa, K.; Murai, M.; Shimatani, Y.; Yoshimoto, T. Transition of fatigue failure mode of Ni-Cr-Mo low-alloy steel in very high cycle regime. Int. J. Fatigue 2010, 32, 541. [CrossRef]

36. Li, Y.D.; Xu, N.; Ma, H.; Li, Y.Z. Granular bright fact crack propagating under very high cycle fatigue. Mater. Sci. Technol. 2016, 31, 1894. [CrossRef]

37. Sakai, T.; Oguma, N.; Morikawa, A. Microscopic and nanoscopic observations of metallurgical structures around inclusions at interior crack initiation site for a bearing steel in very high-cycle fatigue. Fatigue Fract. Eng. Mater. Struct. 2015, 38, 1305. [CrossRef]

38. Lei, Z.Q.; Hong, Y.S.; Xie, J.; Sun, C.Q.; Zhao, A.G. Effects of inclusion size and location on very-high-cycle fatigue behavior for high strength steels. J. Mater. Sci. Eng. A 2012, 558, 234. [CrossRef]

39. Furuya, Y. A New model for predicting the gigacycle fatigue strength of high-strength. J. Mater. Sci. Eng. 2019, 743, 445. [CrossRef] 